\title{
Mechanisms of dysregulation of 11ß-hydroxysteroid dehydrogenase type 1 in obese Zucker rats
}

\author{
D E W Livingstone, C J Kenyon and B R Walker
}

University of Edinburgh, Department of Medical Sciences, Western General Hospital, Edinburgh EH4 2XU, UK

(Requests for offprints should be addressed to B R Walker; Email: B.Walker@ed.ac.uk)

\begin{abstract}
Obesity has been associated with alterations in glucocorticoid metabolism in both man and rodents, but the underlying mechanisms remain undefined. We have previously reported tissue-specific alterations in $11 \beta$ hydroxysteroid dehydrogenase type 1 (11ß-HSD1) in obese Zucker rats predicting that reactivation of corticosterone is decreased in liver but increased in omental fat. The mechanisms of dysregulation of $11 \beta$-HSD 1 in obesity are not known, and in this study we have investigated the potential role of glucocorticoids and insulin. In one experiment lean and obese Zucker rats were adrenalectomised, and in a second experiment they were sensitised to insulin by treatment with either metformin or rosiglitazone.

Adrenalectomy (ADX) of obese animals attenuated weight gain, normalised hepatic $11 \beta-H S D 1$ kinetics by an effect on $V_{\max }$ ( $V_{\max }$ in sham-operated animals, $6.6 \pm 1.1 \mathrm{nmol} / \mathrm{min}$ per $\mathrm{mg}$ in lean vs $3.4 \pm 0.6$ in obese, $P<0 \cdot 01$; in ADX animals $5.9 \pm 1 \cdot 1$ in lean vs $6.9 \pm 1 \cdot 8$ in obese, NS), and reversed the difference in omental fat $11 \beta$-HSD1 activity $(18.9 \pm 4 \cdot 2 \%$ in lean ADX vs $8 \cdot 2 \pm 2 \cdot 3$ in obese ADX, $P=0 \cdot 03)$.
\end{abstract}

Both metformin and rosiglitazone improved insulin sensitivity in obese, but not lean animals, and had no effect on $11 \beta$-HSD1 activity in either liver or fat. However, both treatments normalised adrenal hypertrophy in obese animals $(48 \pm 29 \mathrm{mg}$ in obese vehicle vs $37 \pm 1 \cdot 2$ in metformin and $38 \pm 1.8$ in rosiglitazone treated, both $P<0 \cdot 01$, and rosiglitazone tended to attenuate hypercorticosteronaemia in obese rats. Neither treatment attenuated weight gain; in fact, weight gain was enhanced by rosiglitazone in obese rats.

In summary, altered $11 \beta-H S D 1$ activity in obese Zucker rats is reversible following adrenalectomy, but the mechanism is unclear since adrenalectomy also normalises many other metabolic abnormalities. The current study suggests that hyperinsulinaemia is not responsible for tissue-specific dysregulation of $11 \beta-H S D 1$. However, insulin sensitisation did reverse adrenal hypertrophy, suggesting that hyperinsulinaemia may be a key factor contributing to activation of the hypothalamicpituitary-adrenal (HPA) axis in obesity independently of tissue-specific changes in $11 \beta-\mathrm{HSD} 1$.

Journal of Endocrinology (2000) 167, 533-539

\section{Introduction}

It has been proposed that glucocorticoids are important in primary obesity (Bjorntorp et al. 1999). We have recently described tissue-specific alterations of peripheral glucocorticoid metabolism in the leptin-resistant Zucker rat model of obesity (Livingstone et al. 2000). Reactivation of corticosterone by $11 \beta$-hydroxysteroid dehydrogenase type $1(11 \beta-H S D 1)$ was lower in the liver but higher in adipose tissue when compared with lean Zucker rats. Obese humans also have impaired reactivation of cortisone to cortisol in liver (Stewart et al. 1999), and have similar alterations in urinary glucocorticoid metabolite profiles (Andrew et al. 1998, Stewart et al. 1999). These changes in glucocorticoid metabolism may influence both corticosteroid receptor activation in liver and fat as well as feedback regulation of the hypothalamic-pituitary-adrenal (HPA) axis, and could contribute to increased glucocorticoid secretion in obesity.

The aim of this investigation was to gain insight into the possible mechanisms of dysregulation of $11 \beta-H S D 1$ in obesity. Two of the major regulators of $11 \beta-H S D 1$ are glucocorticoids, which are associated with up-regulation of 11ß-HSD1 activity and expression (Low et al. 1994b), and insulin, which down-regulates $11 \beta-H S D 1$ expression (Hammami \& Siiteri 1991, Jamieson et al. 1995). Obese Zucker rats have increased plasma and urinary glucocorticoid levels when compared with lean animals (Cunningham et al. 1986, Fletcher et al. 1986, GuillaumeGentil et al. 1990, Dryden et al. 1995, Livingstone et al. 2000), and are insulin resistant and hyperinsulinaemic (York et al. 1972). Furthermore, 11ß-HSD activities are disrupted in some other rat models associated with insulin resistance, including Lyon, Bianchi-Milan and 
spontaneously hypertensive rats (Stewart et al. 1993, Takeda et al. 1993, Lloyd-MacGilp et al. 1999). In Zucker obese rats, there is evidence that glucocorticoids contribute to the obesity, since weight gain is attenuated by adrenalectomy or treatment with glucocorticoid receptor antagonists (Yukimura et al. 1978, Freedman et al. 1986, Langley \& York 1990). To investigate whether glucocorticoids and/or insulin have a role in the alterations of $11 \beta-H S D 1$ in Zucker obese rats we carried out two experiments. In one study, Zucker rats were adrenalectomised; in a second study animals were treated with either the biguanide oral hypoglycaemic agent metformin, or the insulin-sensitising peroxisome proliferator-activated receptor- $\gamma(\operatorname{PPAR} \gamma)$ agonist rosiglitazone (BRL 49653).

\section{Materials and Methods}

\section{Animals}

Groups of eight 5-week-old male obese and lean Zucker rats (Harlan Orlac, Bicester, UK) were characterised by phenotype, maintained under controlled conditions of light (on $0800 \mathrm{~h}$ to $2000 \mathrm{~h}$ ) and temperature $\left(21^{\circ} \mathrm{C}\right.$ ), and allowed free access to standard rat chow (Special Diet Services, Witham, UK) and drinking water for 1 week before either surgery or treatment. Animal experiments were carried out under Home Office licence (PPL no. 60/01562).

Six-week-old rats were anaesthetised with $4 \%$ halothane and either bilaterally adrenalectomised (ADX) or sham-operated through dorsal incisions. All rats were then maintained on $0.9 \%$ saline drinking water and weighed every second day.

Alternatively, drug treatment was commenced when the animals were 6 weeks of age. Metformin $(43 \mathrm{mg} / \mathrm{kg}$ body weight) or rosiglitazone (1 mg/ $\mathrm{kg}$ body weight) were administered by gavage daily at $0900 \mathrm{~h}$. Drugs were dissolved in water for administration, and a matched volume of water $(1 \mathrm{ml} / \mathrm{kg})$ was administered daily to the control groups. Animals were weighed regularly to allow accurate dosing with drugs, and to follow the progress of weight gain. Food intake for each cage of four animals was measured daily. After 2 weeks of treatment animals underwent an oral glucose tolerance test which consisted of an overnight fast followed by an oral glucose load of $2 \mathrm{~g} / \mathrm{kg}$ body weight at $0900 \mathrm{~h}$. Blood samples were taken by tail-nick at 0,30 and $120 \mathrm{~min}$ after the glucose bolus and were analysed for glucose and insulin.

At 9 weeks of age, i.e. 3 weeks after surgery or the commencement of drug treatment, animals were decapitated at 0900-1100 h and trunk blood collected. Tissues were dissected and whole adrenals were blotted dry and weighed. Portions of other tissues were snap frozen on dry ice or mechanically homogenised in Krebs Ringer buffer $\left(118 \mathrm{mM} \mathrm{NaCl}, 3.8 \mathrm{mM} \mathrm{KCl}, 1.19 \mathrm{mM} \mathrm{KH}_{2} \mathrm{PO}_{4}\right.$,
$2.54 \mathrm{mM} \mathrm{CaCl}_{2}, 1.19 \mathrm{mM} \mathrm{MgSO}_{4}, 25 \mathrm{mM} \mathrm{NaHCO}$, $\mathrm{pH} 7 \cdot 4)$.

\section{Plasma assays}

Plasma corticosterone levels were measured in terminal blood samples collected at 0900-1100 h using an in-house RIA (Al-Dujaili et al. 1981). The inter- and intra-assay coefficients of variation were $<10 \%$. Glucose concentrations were determined by the hexokinase method using a glucose assay kit (Sigma, Poole, UK), for which the inter- and intra-assay coefficients of variation were both $<2 \%$. Insulin was measured using a rat ${ }^{125}$ I-insulin RIA kit (Amersham, Buckinghamshire, UK), for which the interand intra-assay coefficients of variation were $<15$ and $<10 \%$ respectively.

\section{Measurement of $11 \beta$-HSD1 activity and kinetics}

In vivo $11 \beta-\mathrm{HSD} 1$ is a reductase, converting inactive 11-dehydrocorticosterone to corticosterone. However, in tissue preparations dehydrogenase activity predominates so we quantified $11 \beta-H S D 1$ activity by conversion of corticosterone to 11-dehydrocorticosterone. 11 $\beta$-HSD1 activity was measured in homogenates of tissues by incubating in duplicate at $37^{\circ} \mathrm{C}$ in Krebs Ringer buffer containing $0 \cdot 2 \%$ glucose, NADP $(2 \mathrm{mM})$ and $\left[{ }^{3} \mathrm{H}\right]$ corticosterone $(100 \mathrm{nM})$. Conditions were optimised for each tissue to ensure first-order kinetics and the protein concentrations of homogenates used were $10 \mu \mathrm{g} / \mathrm{ml}$ for liver and $1 \mathrm{mg} / \mathrm{ml}$ for omental fat. After $60 \mathrm{~min}$, steroids were extracted with ethyl acetate, the organic phase evaporated under nitrogen and extracts re-suspended in mobile phase (20\% methanol, $30 \%$ acetonitrile and 50\% water). Steroids were separated by HPLC using a reverse phase $\mu$-Bondapak C18 column and quantified by on-line liquid scintillation counting. In addition, in samples from the adrenalectomy experiment, hepatic 11ß-HSD1 kinetics were determined in microsomes prepared from tissue homogenates as previously described (Livingstone et al. 2000).

\section{Statistics}

All data are expressed as mean \pm standard error. Data were analysed using Student's $t$-test for paired data, or ANOVA followed by post hoc tests.

\section{Results}

\section{Effects of adrenalectomy}

As expected, obese animals gained more weight in the 21-day study period than the lean animals (Table 1) and adrenalectomy attenuated this weight gain. Plasma 
Table 1 Body and organ weights of sham-operated and adrenalectomised lean and obese Zucker rats

\begin{tabular}{|c|c|c|c|c|}
\hline & \multicolumn{2}{|c|}{ Sham-operated } & \multicolumn{2}{|c|}{ Adrenalectomised } \\
\hline & Lean & Obese & Lean & Obese \\
\hline Weight gain, 21 days (g) & $78 \cdot 0 \pm 4 \cdot 4$ & $104 \cdot 1 \pm 4 \cdot 0^{*}$ & $38 \cdot 8 \pm 3 \cdot 8$ & $50 \cdot 5 \pm 6 \cdot 2$ \\
\hline Adrenal weight (mg) & $38 \cdot 4 \pm 2 \cdot 1$ & $54 \cdot 3 \pm 6 \cdot 8^{*}$ & n.d. & n.d. \\
\hline Adrenal weight/ & & & & \\
\hline body weight (mg/g) & $0 \cdot 17 \pm 0 \cdot 01$ & $0 \cdot 20 \pm 0.03$ & - & - \\
\hline Plasma corticosterone (nM) & $78 \pm 48$ & $446 \pm 91^{*}$ & n.d. & n.d. \\
\hline
\end{tabular}

Data are means \pm S.E.M.s; ${ }^{*}<<0.05$ compared with lean sham-operated group. n.d., not detectable; limit of detection for corticosterone RIA was $6 \cdot 25 \mathrm{nM} . n=8$ in all groups, except lean adrenalectomised where $n=7$.

corticosterone levels were significantly elevated in shamoperated obese Zucker rats, and corticosterone was not detected in the plasma of any of the adrenalectomised animals.

Hepatic 11ß-HSD1 kinetics were analysed using the Lineweaver-Burke linear transformation of the Michaelis-Menten equation (Lineweaver \& Burke 1934). The Michaelis constant $\left(K_{\mathrm{m}}\right)$ was not different between lean and obese animals and was unaffected by adrenalectomy. Maximum velocity $\left(V_{\max }\right)$ values for obese animals were approximately half those for lean animals (Fig. 1). Adrenalectomy normalised $V_{\max }$ in obese animals but had no effect in lean animals.

$11 \beta$-HSD1 activity in omental fat tended to be higher in obese than lean rats $(P=0 \cdot 13$; Fig. 2$)$. Adrenalectomy tended to decrease omental fat $11 \beta$-HSD1 activity in obese rats, but increase it in lean rats, so that after adrenalectomy enzyme activity was lower rather than higher in obese animals $(P=0 \cdot 03)$.

\section{Effects of insulin-sensitising drugs}

By contrast with adrenalectomy, neither of the antidiabetic treatments attenuated weight gain; in fact rosiglitazone caused an increase in weight gain and food intake (Table 2).

Results from glucose tolerance tests are shown in Fig. 3. Obese animals exhibited hyperglycaemia in the fasting state and $120 \mathrm{~min}$ after the glucose bolus. Insulin levels were markedly higher in obese animals at all time points in the glucose tolerance test. Neither metformin nor rosiglitazone affected plasma glucose or insulin in lean rats. In obese rats effects on plasma insulin were more striking than effects on plasma glucose: metformin decreased both fasting and $30 \mathrm{~min}$ plasma glucose levels, and decreased $30 \mathrm{~min}$ and $120 \mathrm{~min}$ insulin levels; rosiglitazone decreased only the $30 \mathrm{~min}$ glucose level, but reduced plasma insulin levels at all time points.

Plasma corticosterone levels were rather variable in this experiment, probably reflecting poorly controlled stress at the time of decapitation (this experiment was performed in a different animal unit from the adrenalectomy experiment), so that trends rather than statistically significant differences were observed (Table 2). In lean animals, neither plasma corticosterone nor adrenal weight was affected by metformin or rosiglitazone. However, in obese animals, where plasma corticosterone and adrenal weight were higher, both metformin and rosiglitazone reduced adrenal weight, but only rosiglitazone reduced plasma corticosterone (Table 2).

In vehicle treated animals, hepatic $11 \beta-$ HSD 1 activity (Fig. 4a) was lower, and omental fat 11ß-HSD1 activity (Fig. $4 b)$ was higher $(P=0.02)$, in obese than in lean rats. Neither metformin nor rosiglitazone altered hepatic or omental fat 11ß-HSD1 activity.

\section{Discussion}

These data confirm previous reports that obese Zucker rats show activation of the HPA axis (Livingstone et al. 2000), impaired glucose tolerance and insulin resistance (York et al. 1972), and tissue-specific alterations in peripheral corticosterone metabolism (Livingstone et al. 2000). In addition, we found that adrenalectomy had tissuespecific effects to normalise $11 \beta-H S D 1$ activity: impaired $11 \beta$-HSD1 activity in liver of obese rats was restored; enhanced 11 $\beta-$ HSD1 activity in omental fat of obese rats was reduced. In contrast, insulin sensitisation with metformin or rosiglitazone had no effect on aberrant $11 \beta-H S D 1$ activity in either tissue, but normalised the adrenal hypertrophy in obese rats.

Normalisation of weight gain in obese rats by adrenalectomy has been reported previously (Yukimura et al. 1978), and is associated with normalisation of many of their metabolic abnormalities, including hyperinsulinaemia (Castonguay et al. 1986). The current data show that reversal of this metabolic syndrome by adrenalectomy is associated with normalisation of hepatic $11 \beta-H S D 1$ kinetics, i.e. an increase in $V_{\max }$ without altering $K_{\mathrm{m}}$. The kinetic data suggest that the abnormality in hepatic $11 \beta$ HSD1 in the obese Zucker rat is due to down-regulation 


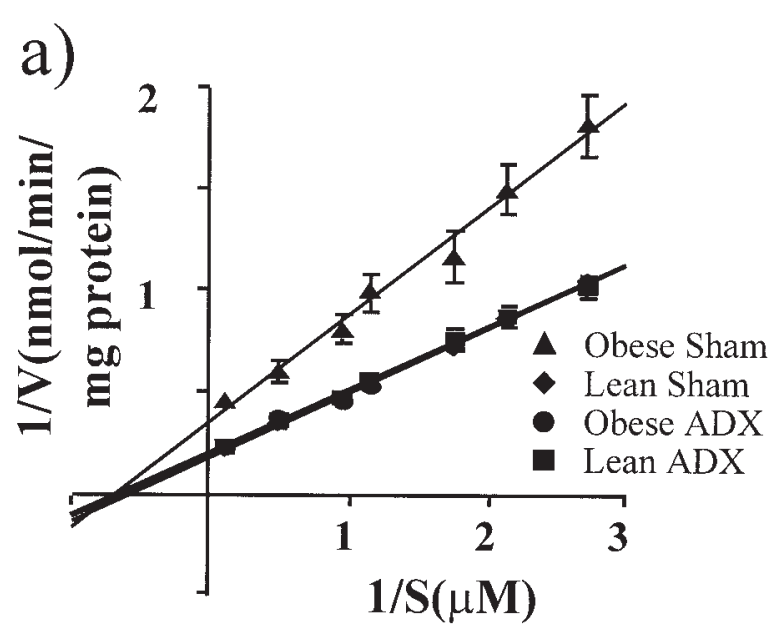

b)
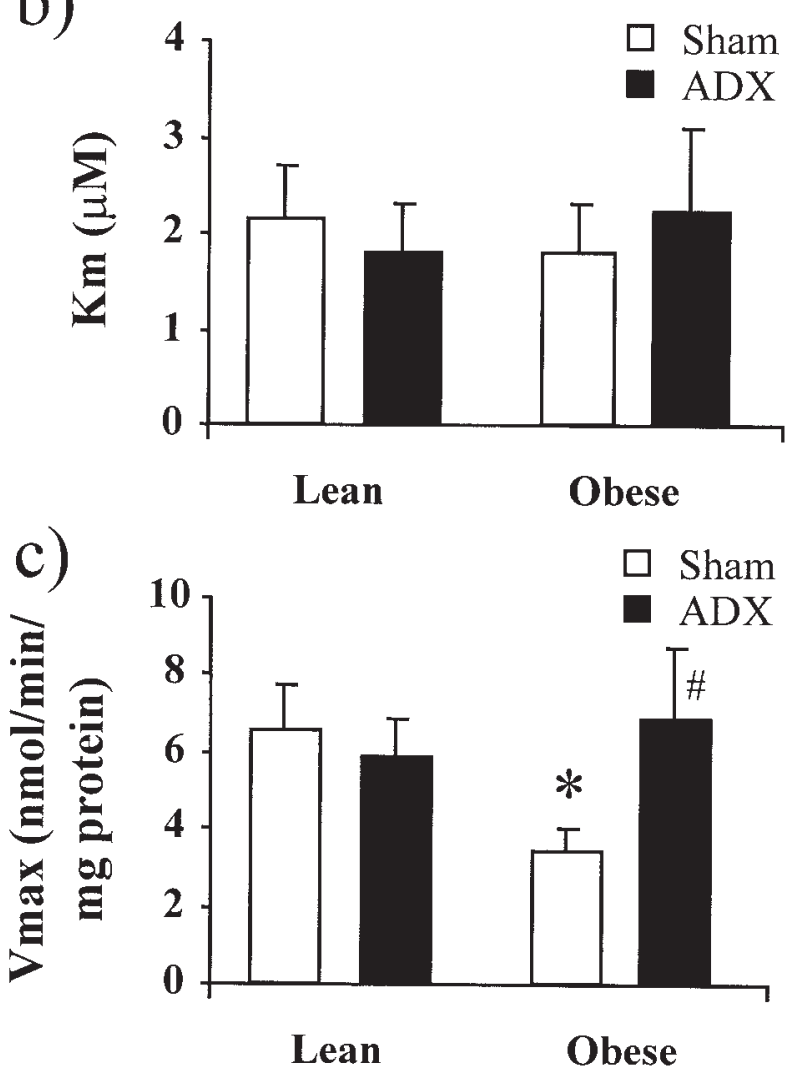

Figure 1 Hepatic $11 \beta$-HSD1 kinetics from adrenalectomy experiment. Data are means \pm S.E.M.s. ${ }^{\star} P<0 \cdot 05$ comparing lean and obese sham-operated animals; $\# P<0.05$ compared with sham-operated animals of the same phenotype; Sham denotes sham-operated animals; and ADX denotes adrenalectomised animals. (a) Lineweaver-Burke plots for summarised data. $K_{\mathrm{m}}$ (b) and $V_{\max }$ (c) were calculated from Lineweaver-Burke plots for each individual animal. $n=8$ in all groups except lean adrenalectomised where $n=7$.

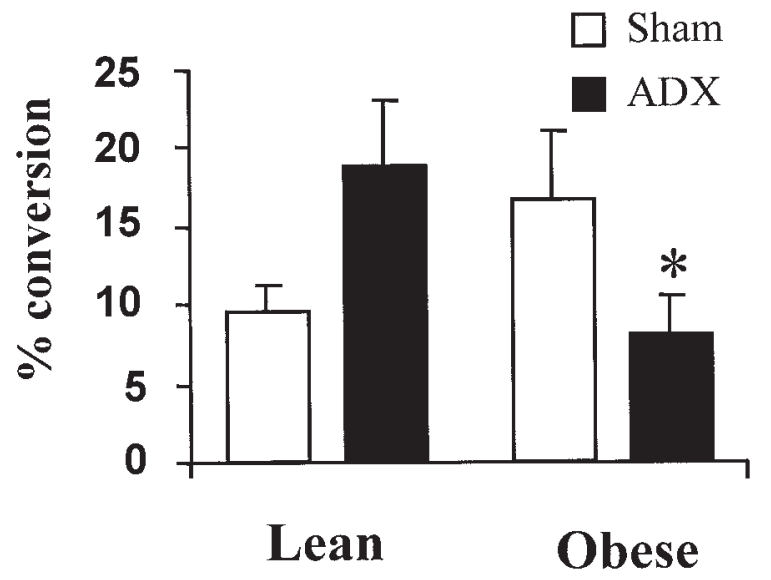

Figure $211 \beta$-HSD1 activity in omental fat from adrenalectomy experiment. Data are means \pm S.E.M.s; Sham denotes sham-operated animals and ADX denotes adrenalectomised animals. $11 \beta$-HSD1 activity was assessed as percentage conversion of corticosterone to 11-dehydrocorticosterone. ${ }^{*} P<0.05$ comparing lean and obese animals receiving the same treatment. $n=8$ in all groups except lean adrenalectomised where $n=7$.

of protein, and that normalisation of enzyme activity is due to an increase in protein, rather than removal of a competitive inhibitor. One explanation for this is that hypercorticosteronaemia is responsible for dysregulation of $11 \beta-H S D 1$ activity in obesity. However, it is difficult to address this directly because any manipulation which restores circulating glucocorticoid levels in adrenalectomised obese rats also restores additional metabolic disturbances such as hyperinsulinaemia (Freedman et al. 1986).

The alterations in 11ß-HSD1 in omental fat in obese Zucker rats are qualitatively different from those in liver. The current results confirm increased $11 \beta-H S D 1$ activity in omental fat from obese animals (Livingstone et al. 2000), albeit that this was statistically significant in the insulinsensitising experiment but a non-significant trend in the sham-adrenalectomised animals. After adrenalectomy, this difference was reversed, so that omental fat 11 $\beta$-HSD1 activity was lower in obese animals. Relatively little is known about regulation of $11 \beta-H S D 1$ expression in rat adipose tissue, but experiments in human cultured cells suggest that both glucocorticoids and insulin may up-regulate activity (Bujalska et al. 1997). However, our observation that adrenalectomy up-regulates $11 \beta$-HSD1 activity in omental fat of lean animals, by contrast with the lack of effect in liver of lean rats, reinforces previous observations that regulation of this enzyme is tissue specific (Low et al. 1994b), and suggests that it is unlikely that chronic hypercorticosteronaemia is responsible for up-regulation of adipose $11 \beta-H S D 1$ in obese Zucker rats.

An alternative explanation for the effect of adrenalectomy is that reversal of insulin resistance is important, as 
Table 2 Body and organ weights of lean and obese Zucker rats treated with vehicle, metformin or rosiglitazone

\begin{tabular}{|c|c|c|c|c|c|c|}
\hline & \multicolumn{2}{|l|}{ Vehicle } & \multicolumn{2}{|l|}{ Metformin } & \multicolumn{2}{|c|}{ Rosiglitazone } \\
\hline & Lean & Obese & Lean & Obese & Lean & Obese \\
\hline Weight gain, 21 days (g) & $93 \pm 5 \cdot 5$ & $137 \pm 3 \cdot 8^{*}$ & $90 \pm 4 \cdot 8$ & $133 \pm 1 \cdot 8^{*}$ & $89 \pm 5 \cdot 7$ & $152 \pm 3 \cdot 5 * \#$ \\
\hline Adrenal weight $(\mathrm{mg})$ & $37 \cdot 4 \pm 3 \cdot 5$ & $48 \cdot 4 \pm 2 \cdot 9^{*}$ & $32 \cdot 9 \pm 2 \cdot 7$ & $36 \cdot 9 \pm 1 \cdot 2 \#$ & $36 \cdot 2 \pm 1 \cdot 9$ & $37 \cdot 8 \pm 1 \cdot 8 \#$ \\
\hline Adrenal weight/body weight $(\mathrm{mg} / \mathrm{kg})$ & $158 \pm 15$ & $153 \pm 10$ & $140 \pm 13$ & $112 \pm 4 \cdot 6^{*} \#$ & $153 \pm 9 \cdot 5$ & $107 \pm 3 \cdot 8^{*} \#$ \\
\hline Plasma corticosterone $(\mathrm{nM})$ & $163 \pm 74$ & $302 \pm 86$ & $175 \pm 48$ & $340 \pm 113$ & $178 \pm 46$ & $160 \pm 56$ \\
\hline
\end{tabular}

Data are means \pm S.E.M.s; ${ }^{*} P<0.05$ comparing lean and obese animals receiving the same treatment; \#P<0.05 compared with animals of the same phenotype receiving vehicle. $n=8$ in all groups.

insulin down-regulates $11 \beta$-HSD1 activity in liver (Hammami \& Siiteri 1991) and may up-regulate it in fat (Bujalska et al. 1997). Both metformin and rosiglitazone enhanced insulin sensitivity in obese, but not lean, Zucker rats. The mechanism of their action is probably different, with metformin lowering fasting glucose and acting principally on hepatic gluconeogenesis, while rosiglitazone may have more important effects in adipose tissue. While metformin treatment had no effect on food intake or body weight, rosiglitazone treatment caused an increase in both food intake and weight gain in obese animals, as previously reported (Wang et al. 1997). However, neither
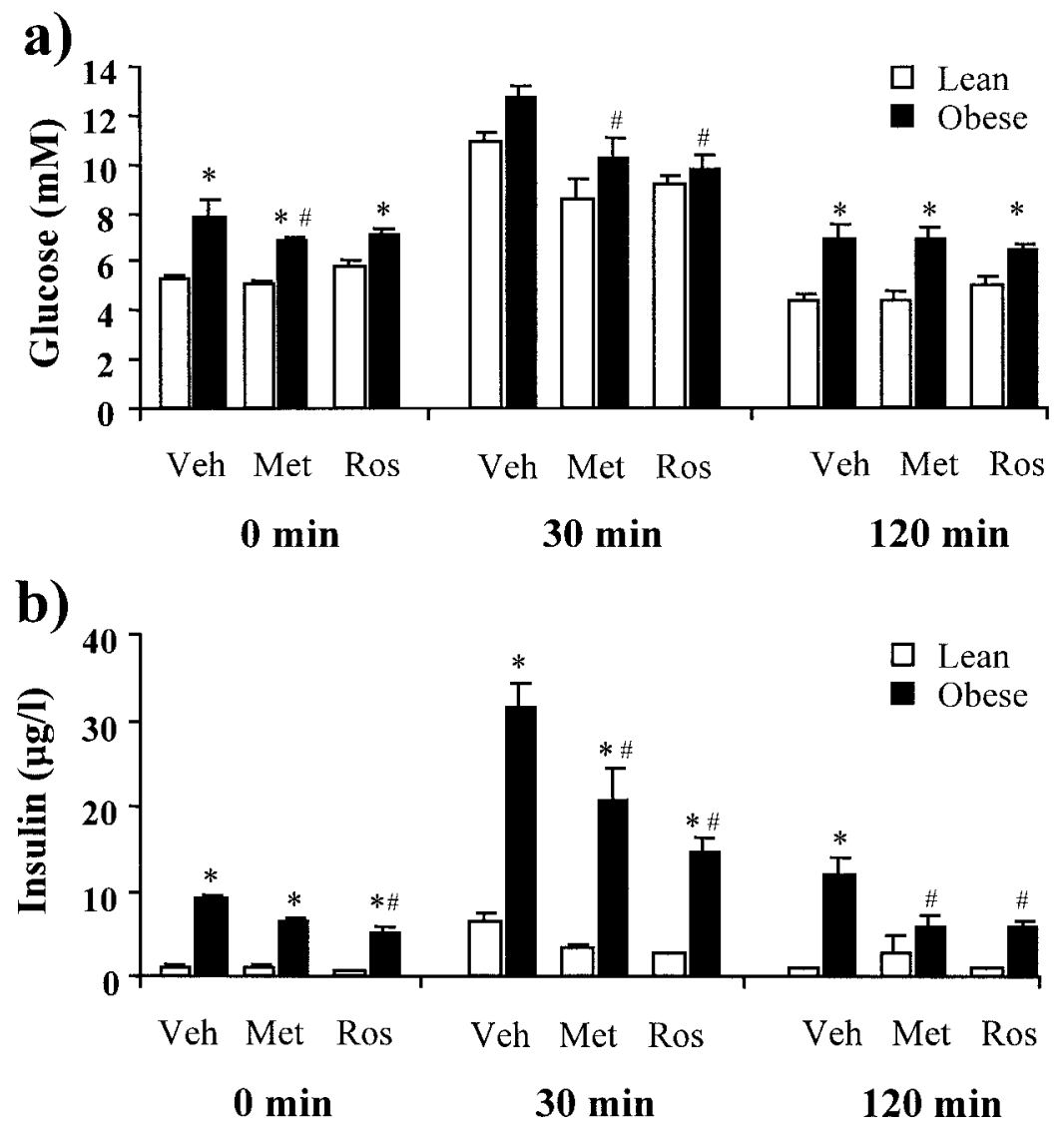

Figure 3 Glucose tolerance tests from insulin-sensitising experiment. Data are means \pm S.E.M.s; ${ }^{*} P<0 \cdot 05$ comparing lean and obese animals receiving the same treatment; $\# P<0.05$ compared with animals of the same phenotype receiving vehicle. Veh denotes vehicle-treated animals; Met, metformin treatment; and Ros, rosiglitazone treated. (a) Glucose levels and (b) insulin levels at 0,30 and 120 min after a bolus of $2 \mathrm{~g} / \mathrm{kg}$ glucose. $n=8$ in all groups. 


\section{a) Liver}

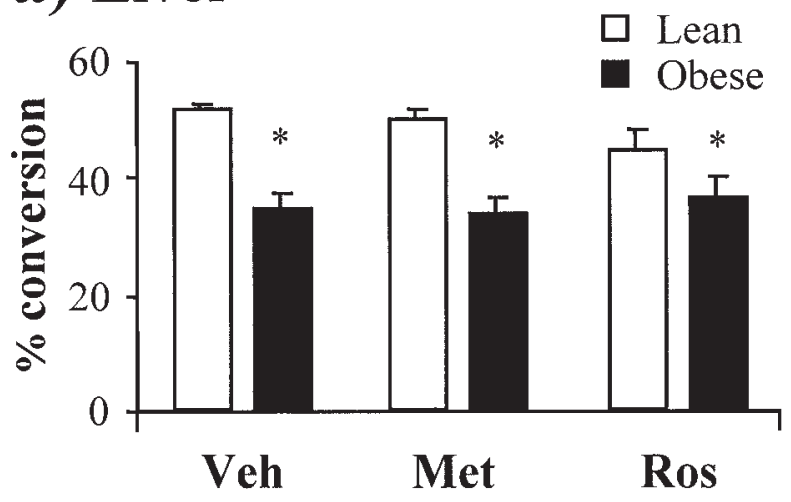

\section{b) Omental fat}

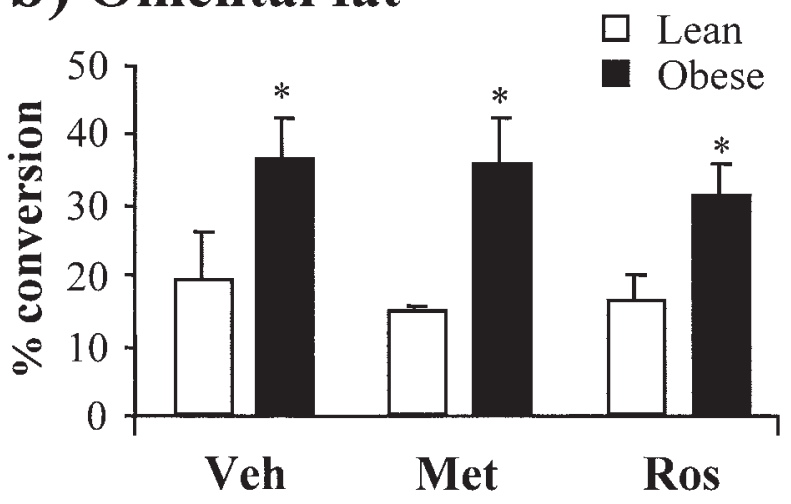

Figure $411 \beta$-HSD1 activities from insulin-sensitising experiments. Data are means \pm S.E.M.s; ${ }^{*} P<0.05$ comparing lean and obese animals receiving the same treatment; $\# P<0.05$ compared with animals of the same phenotype receiving vehicle. Veh denotes vehicle-treated animals; Met, metformin treatment; and Ros, rosiglitazone treated. $11 \beta$-HSD1 activity was assessed as percentage conversion of corticosterone to 11 -dehydrocorticosterone. $n=8$ in all groups.

insulin-sensitising agent affected $11 \beta-H S D 1$ activity in liver or adipose tissue.

Mechanisms for activation of the HPA axis in obesity are poorly understood. Enhanced peripheral glucocorticoid clearance, resulting from increased $5 \alpha$-reductase and impaired hepatic 11ß-HSD1 activities (Livingstone et al. 2000), may be an important stimulus (Strain et al. 1982). However, although neither metformin nor rosiglitazone affected 11 $\beta$-HSD1 activity in peripheral tissues, both treatments normalised the adrenal hypertrophy in obese Zucker rats. Moreover, there was a trend for normalisation of plasma corticosterone by rosiglitazone, albeit contrary to a previous report (Wang et al. 1997). Effects on adrenal size without changes in plasma glucocorticoid levels may reflect actions of insulin-sensitising agents on other glucocorticoid-metabolising enzymes, such as $5 \alpha-$ reductase. Alternatively, insulin increases activity and expression of the steroidogenic enzyme $3 \beta$-hydroxysteroid dehydrogenase in the adrenal cortex (Kristiansen et al. 1997), and impaired steroidogenesis in insulin resistance could play a role in adrenal hypertrophy in the obese Zucker rat. Effects on adrenal size accompanied by a reduction in plasma corticosterone are more consistent with effects of insulin resistance or hyperinsulinaemia on central control of the HPA axis. Further studies of the effects of insulin on the HPA axis in insulin-resistant models are required to differentiate these possibilities.

In conclusion, in obesity down-regulation of $11 \beta-$ HSD1 may attenuate glucocorticoid action in liver and may enhance metabolic clearance of glucocorticoids. By contrast, enhanced $11 \beta-H S D 1$ in omental fat may maintain local glucocorticoid concentrations and promote lipogenesis. Both of these phenomena are reversible following adrenalectomy, but the mechanism is unclear and does not appear to relate to hyperinsulinaemia. Alternative mediators of tissue-specific dysregulation of $11 \beta$-HSD1, including growth hormone (Low et al. 1994a) and gonadal steroids (Low et al. 1993), may be more important in obesity. However, hyperinsulinaemia may be a key factor contributing to activation of the HPA axis in obesity independently of tissue-specific changes in $11 \beta-H S D 1$.

\section{Acknowledgements}

This work was supported by fellowships from the University of Edinburgh Faculty of Medicine (DEWL) and the British Heart Foundation (BRW), and grants from the Medical Research Council (CJK). Rosiglitazone was a gift from SmithKline-Beecham.

\section{References}

Al-Dujaili EAS, Williams BC \& Edwards CRW 1981 The development and application of a direct radioimmunoassay for corticosterone. Steroids 37 157-176.

Andrew R, Phillips DIW \& Walker BR 1998 Obesity and gender influence cortisol secretion and metabolism in man. Journal of Clinical Endocrinology and Metabolism 83 1806-1809.

Bjorntorp P, Holm G \& Rosmond R 1999 Hypothalamic arousal, insulin resistance and type 2 diabetes mellitus. Diabetic Medicine 16 373-381.

Bujalska IJ, Kumar S \& Stewart PM 1997 Does central obesity reflect 'Cushing's disease of the omentum'? Lancet 349 1210-1213.

Castonguay TW, Dallman MF \& Stern JS 1986 Some metabolic and behavioural effects of adrenalectomy on obese Zucker rats. American Journal of Physiology 251 R923-R933.

Cunningham JJ, Calles-Escandon J, Garrido F, Carr DB \& Bode HH 1986 Hypercorticosteronuria and diminished pituitary responsiveness to corticotropin-releasing factor in obese Zucker rats. Endocrinology 118 98-101.

Dryden S, Pickavance L, Frankish HM \& Williams G 1995 Increased neuropeptide Y secretion in the hypothalamic paraventricular nucleus of obese $(\mathrm{fa} / \mathrm{fa})$ Zucker rats. Brain Research 690 185-188.

Fletcher JM, Haggarty P, Wahle KWJ \& Reeds PJ 1986 Hormonal studies of young lean and obese Zucker rats. Hormone and Metabolism Research 18 290-295. 
Freedman MR, Horwitz BA \& Stern JS 1986 Effect of adrenalectomy and glucocorticoid replacement on development of obesity. American Journal of Physiology 252 R595-R607.

Guillaume-Gentil C, Rohner-Jeanrenaud F, Abramo F, Bestetti GE, Rossi GL \& Jeanrenaud B 1990 Abnormal regulation of the hypothalamo-pituitary-adrenal axis in the genetically obese $f a / f a$ rat. Endocrinology 126 1873-1879.

Hammami MM \& Siiteri PK 1991 Regulation of $11 \beta$-hydroxysteroid dehydrogenase activity in human skin fibroblasts: enzymatic modulation of glucocorticoid action. Journal of Clinical Endocrinology and Metabolism 73 326-334.

Jamieson PM, Chapman KE, Edwards CRW \& Seckl JR 1995 $11 \beta$-Hydroxysteroid dehydrogenase is an exclusive $11 \beta$-reductase in primary cultures of rat hepatocytes: effect of physicochemical and hormonal manipulations. Endocrinology 136 4754-4761.

Kristiansen SB, Endoh A, Casson PR, Buster JE \& Hornsby PJ 1997 Induction of steroidogenic enzyme genes by insulin and IGF-I in cultured adult human adrenocortical cells. Steroids 62 258-265.

Langley SC \& York DA 1990 Effect of antiglucocorticoid RU486 on development of obesity in obese fa/fa Zucker rats. American Journal of Physiology 259 R539-R544.

Lineweaver H \& Burke D 1934 The determination of enzyme dissociation constants. Journal of the American Chemical Society 56 658-666.

Livingstone DEW, Jones GC, Smith K, Andrew R, Kenyon CJ \& Walker BR 2000 Understanding the role of glucocorticoids in obesity: tissue-specific alterations of corticosterone metabolism in obese Zucker rats. Endocrinology 141 560-563.

Lloyd-MacGilp SA, Nelson SM, Florin M, Lo M, McKinnell J, Sassard J \& Kenyon CJ 1999 11ß-Hydroxysteroid dehydrogenase and corticosteroid action in Lyon hypertensive rats. Hypertension 34 $1123-1128$.

Low SC, Assaad SN, Rajan V, Chapman KE, Edwards CRW \& Seckl JR 1993 Regulation of $11 \beta$-hydroxysteroid dehydrogenase by sex steroids in vivo: further evidence for the existence of a second dehydrogenase in rat kidney. Journal of Endocrinology 139 27-35.
Low SC, Chapman KE, Edwards CRW, Wells T, Robinson ICAF \& Seckl JR 1994a Sexual dimorphism of hepatic 11ß-hydroxysteroid dehydrogenase in the rat: the role of growth hormone patterns. Journal of Endocrinology 143 541-548.

Low SC, Moisan M-P, Noble JM, Edwards CRW \& Seckl JR $1994 b$ Glucocorticoids regulate hippocampal 11 $\beta$-hydroxysteroid dehydrogenase activity and gene expression in vivo in the rat. Journal of Neuroendocrinology 6 285-290.

Stewart PM, Whorwood CB, Valentino R, Burt D, Sheppard MC \& Edwards CRW 1993 11-Beta-hydroxysteroid dehydrogenase activity and gene expression in the hypertensive Bianchi-Milan rat. Journal of Hypertension 11 349-354.

Stewart PM, Boulton A, Kumar S, Clark PMS \& Shackleton CHL 1999 Cortisol metabolism in human obesity: impaired cortisone-cortisol conversion in subjects with central adiposity. Journal of Clinical Endocrinology and Metabolism 84 1022-1027.

Strain GW, Zumoff B, Kream J, Strain JJ, Levin J \& Fukushima D 1982 Sex difference in the influence of obesity on the $24 \mathrm{hr}$ mean plasma concentration of cortisol. Metabolism 31 209-212.

Takeda Y, Yoneda T, Miyamori I, Gathiram P \& Takeda R 1993 $11 \beta$-Hydroxysteroid dehydrogenase activity in mesenteric arteries of spontaneously hypertensive rats. Clinical and Experimental Pharmacology and Physiology 20 627-631.

Wang Q, Dryden S, Frankish HM, Bing C, Pickavance L, Hopkins D, Buckingham RE \& Williams G 1997 Increased feeding in fatty Zucker rats by the thiazolidinedione BRL 49653 (rosiglitazone) and the possible involvement of leptin and hypothalamic neuropeptide Y. British Journal of Pharmacology 122 1405-1410.

York DA, Steinke J \& Bray GA 1972 Hyperinsulinaemia and insulin resistance in genetically obese rats. Metabolism 21 277-284.

Yukimura Y, Bray GA \& Wolfsen AR 1978 Some effects of adrenalectomy in the fatty rat. Endocrinology 103 1924-1928.

Received 30 May 2000

Accepted 2 August 2000 